\title{
Endodontics Review \\ A Study Guide
}

Authors: Brooke Blicher / Rebekah Lucier Pryles / Jarshen Lin

Publisher: Quintessence Publishing

Language: English

ISBN: 978-0-86715-696-6

Edition: $1 / \mathrm{e}$

Publish Year: 2016

Pages: 264, illustrated

Price: $68.00 €$

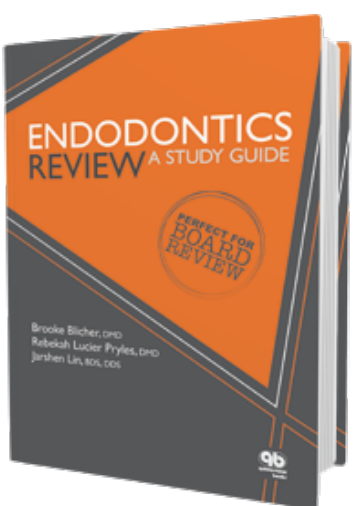

The book entitled "Endodontics Review: A Study Guide" is endorsed by the American Board of Endodontics (ABE) and provides information for the written and oral sections of the ABE examination. The book is divided into 12 chapters. The chapters follow the structure of the oral examination: basic sciences, medicine, diagnosis, treatment protocols, prognosis, and complications. To better understand the endodontic diagnosis and treatment protocols it is necessary to have strong knowledge of normal development, histology, physiology, microbiology, anatomy, pathology and pharmacology. This book provides all of the above and helps the candidate to be successful in the ABE exam and to also have an overall picture of the domain.

DOI: 10.25241/stomaeduj.2017.4(3).bookreview.4

\section{Iulia}

Ciolachi

DMD

Holistic Dental \& Medical Institute of Bucharest-ROPOSTURO, Bucharest,

Romania

e-mail:

dr.iuliaciolachi@yahoo.ro 